\title{
Aerobic Bacterial Profile of Post-Operative Wound Infections and their Antibiotic Susceptibility Pattern
}

\author{
P. Preethishree ${ }^{1 *}$, Rekha Rai ${ }^{2}$ and K. Vimal Kumar ${ }^{2}$ \\ ${ }^{1}$ Department of Microbiology, Yenepoya Medical College, Mangalore, Karnataka, India \\ ${ }^{2}$ Department of Microbiology, K. S. Hegde Medical Academy, Mangalore, Karnataka, India \\ *Corresponding author
}

\section{A B S T R A C T}

\begin{tabular}{|c|c|}
\hline & \multirow{9}{*}{$\begin{array}{l}\text { Post-operative wound infections remain a serious problem in spite of modern standards of pre- } \\
\text { operative preparation, antibiotic prophylaxis and operative technique. This study was } \\
\text { undertaken to Isolate aerobic bacterial pathogens from clinically suspected post-operative } \\
\text { wound infections and to determine their antibiogram. Samples that were sent to Microbiology } \\
\text { laboratory from clinically suspected cases of post-operative wound infections were processed } \\
\text { further. The bacteria isolated on aerobic culture were identified to the species level by standard } \\
\text { biochemical tests. Antibiotic sensitivity testing, phenotypic identification of MRSA and ESBL } \\
\text { producers were done as per CLSI guidelines. Overall incidence of post-operative wound } \\
\text { infection was } 1.7 \% \text {. Majority of the patients }(53.66 \%) \text { presented with SSI during the post- } \\
\text { operative period of } 3-10 \text { days. } 49 \text { samples showed culture positivity out of } 82 \text { infected cases. } \\
\text { S.aureus was the predominant isolate }(73.47 \%) \text { followed by E.coli, K.pneumoniae, } \\
\text { P.aeruginosa and P.mirabilis. MRSA accounted for } 22.22 \% \text {. All the S.aureus isolates were } \\
\text { sensitive to Linezolid and Vancomycin. } 75 \% \text { of Enterobacteriaceae produced ESBL among } \\
\text { which } 66.67 \% \text { were E.coli and } 33.33 \% \text { were K.pneumoniae. Marked resistance of isolates to } \\
\text { commonly used antibiotics indicates the need for judicious use of these drugs to prevent the } \\
\text { emergence of multi drug resistant strains. Proper infection control measures and a sound } \\
\text { antibiotic policy are necessary to reduce post-operative wound infections. }\end{array}$} \\
\hline Keywords & \\
\hline & \\
\hline & \\
\hline & \\
\hline & \\
\hline & \\
\hline & \\
\hline & \\
\hline
\end{tabular}

\section{Introduction}

Post-operative wound infections or Surgical Site Infections (SSI) are defined as infections occurring within 30 days after operation for superficial incisional SSI and for operations without implant in place; within 1 year if implant is in place (as per CDC guidelines 1999). However the recent guideline states that infections occurring within 90 days (if implant is in place) are considered as SSI for deep incisional SSI and organ space SSI (CDC 2015 guidelines). Post-operative wound infections are one of the health care associated infections which account for $22 \%$ of HCAI, and are second most common HCAI (Gupta, 2012). In India, the SSI incidence varies from $4.04 \%$ to $30 \%$ (Bangal et al., 2014). Three major factors contribute to post-operative wound infection: a) degree of microbial contamination of the wound during surgery, b) duration of operative procedure, c) host factors (age, obesity, malnutrition, diabetes, carrier state i.e., chronic Staphylococcal carriage, immunosuppression, anaemia, renal failure, radiation etc) (Beilman et al., 2015, Barie, 2012). 
Microbiology of SSI depends on the nature of surgery, incision location and body cavity/hollow viscous entry during the procedure. Skin flora is responsible for most of the SSI as they are inoculated into the incision during operation (Barie, 2012).

Most common appearance of SSI is between the 5th and 10th day after operation (Verma et al., 2012). Post-operative wound infections can be caused through exogenous or endogenous bacteria (Shanthi et al., 2012).

As per the data obtained from the National Nosocomial Infections Surveillance System of the CDC 2007, Staphylococcus aureus and Streptococcus pyogenes are the most common causative agents in clean surgery.

The common organisms associated with abdominal and gynaecological surgeries are Escherichia coli, Klebsiella species, Pseudomonas species, Acinetobacter species, Staphylococcus aureus and Streptococcus species.

Urological surgeries commonly have infections with Pseudomonas species and Acinetobacter species. Staphylococcus aureus and gram negative bacilli are commonly found in infections of Orthopaedic surgeries (Gupta, 2012).

Post-operative wound infections are associated with considerable morbidity and mortality, substantial health care costs, delayed recovery and prolonged stay in hospital by a median of 2 weeks.

There is risk of acquiring SSI even after discharge and the incidence is $2 \%$. Also, these patients are more likely to be readmitted to the hospital (Kitembo et al., 2013).

Increase in multidrug resistant microorganisms is causing a serious therapeutic problem for surgeons. Hence it is necessary to know the prevalent organisms and their antibiogram for early initiation of the treatment (Bibi et al., 2012). Though it is not possible to eliminate post-operative wound infections, they can be reduced to a minimal level which could benefit the patient as well as the medical resources used (Shanthi et al., 2012).

This study was undertaken to study the aerobic bacterial profile of post-operative wound infections and to determine their antibiotic susceptibility pattern.

To isolate the aerobic bacterial pathogens from clinically suspected post-operative wound infections and also to determine their antibiogram.

\section{Materials and Methods}

This study was conducted in the department of Microbiology in a tertiary care hospital in Mangaluru, from October 2013 to March 2015. The material for the study was obtained from the samples (of patients with signs and symptoms of post-operative wound infections) that were sent to the department of Microbiology from various surgical units.

\section{Inclusion criteria}

1. Age > 18years; 2. Surgical procedures performed within any of the following designated surgical services: General surgery, Orthopaedics, Obstetrics and Gynaecology (OBG) 3. Exudate samples from Surgical Site Infection

\section{Exclusion criteria}

1. Age < 18 years; 2. Surgical procedures performed in departments other than general surgery/orthopaedics/OBG; 3. Infected burn wounds; 4. Stitch abscess; 5. Episiotomy wound infection. 


\section{Methods of processing}

Direct microscopic examination of the gram stained smear. Sample inoculation onto plates of MacConkey agar and 5\% sheep blood agar by rolling over the agar and streaking from primary inoculum using a sterile bacteriological loop. The plates were then incubated aerobically at $37^{\circ} \mathrm{C}$ for 24 hours and if there was no growth, it was further incubated for 48 hours. Any growth on the media was further identified to the species level using relevant biochemical tests.

Antibiotic susceptibility testing was done on Mueller Hinton Agar using Kirby Bauer's disc diffusion method, according to CLSI guidelines.

Phenotypic identification and detection of Methicillin Resistant Staphylococcus aureus (MRSA) and Extended Spectrum Beta Lactamase (ESBL) producers as per CLSI guidelines.

All the Staphylococcus aureus isolates were screened for mecA-Mediated Oxacillin resistance using the surrogate marker cefoxitin $(30 \mu \mathrm{g})$.

\section{Quality control}

S. aureus ATCC 25923 - mecA negative S. aureus ATCC $43300-$ mecA positive

\section{Screening test for detection of inducible clindamycin resistance}

All the Staphylococcal isolates were screened for detection of inducible Clindamycin resistance by disk diffusion method by placing Erythromycin $(15 \mu \mathrm{g})$ and Clindamycin $(2 \mu \mathrm{g})$ which were placed $15-26$ $\mathrm{mm}$ apart. Presence of a D-zone (flattening of the inhibition zone adjacent to Erythromycin disk) indicated that the isolate had inducible resistance to Clindamycin.

\section{Detection of Extended Spectrum Beta Lactamase (ESBL) production}

This method was performed for Escherichia coli and Klebsiella pneumoniae isolates in our study.

\section{Screening test}

Initial screen test was done by disk diffusion method on Mueller Hinton Agar (MHA). The test colony suspension of turbidity of $0.5 \mathrm{Mc}$ Farland was lawn cultured onto MHA and Ceftazidime $30 \mu \mathrm{g}$ and Cefotaxime $30 \mu \mathrm{g}$ disks were placed. It was then incubated $37^{\circ} \mathrm{C}$, ambient air, for 16-18 hours. Ceftazidime zone of $\leq 22 \mathrm{~mm}$ and Cefotaxime zone of $\leq 27 \mathrm{~mm}$ were considered to be positive for ESBL screening. Quality control strain: Klebsiella pneumoniae ATCC 700603

\section{Phenotypic confirmatory test}

Confirmatory test for ESBL production was carried out by Disk Diffusion method. The test colony suspension of turbidity of $0.5 \mathrm{Mc}$ Farland was lawn cultured onto MHA and following antimicrobial disks were placed: Ceftazidime 30 $\mathrm{g}$; Ceftazidime-clavulanate

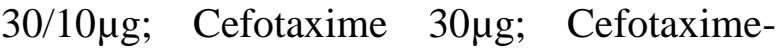
clavulanate $30 / 10 \mu \mathrm{g}$. It was then incubated at $37^{\circ} \mathrm{C}$, ambient air, for $16-18$ hours. $\mathrm{A} \geq 5 \mathrm{~mm}$ increase in a zone diameter for either antimicrobial agent tested in combination with clavulanate v/s the zone diameter of the agent when tested alone was confirmed for ESBL production.

\section{Results and Discussion}

Incidence of post-operative wound infection (Table 1)

A total of 4,829 surgeries were performed during the study period in the department of Orthopaedics (2,290), Obstetrics and Gynaecology (873) and Surgery (1,666). 
Eighty two of these patients suffered from post-operative wound infection. The overall infection rate is being $1.7 \%$.

Our finding is similar to a study by Shah et al., (2015) from Mumbai, who reported an overall incidence of $1.6 \%$. Bangal et al., (2014), Golia et al., (2014), Korol et al., (2013), have reported SSI incidence of $<5 \%$. In contrary, studies by Mundhada et al., (2015) and Mawalla et al., (2011) have reported a higher incidence of SSI.

The incidence of post-operative wound infection was $4.01 \%$ in obstetrics and gynaecological surgeries in this study. Incidence of $2.8 \%, 6.12 \%$ and $7.47 \%$ has been reported by Bangal et al., (2014) from Loni, Bhadauria et al., (2013) from Wardha and Rahman et al., (2011) from Dhaka respectively. Devjani et al., (2013) from New Delhi reported a higher incidence of SSI (24.2\%).

The incidence of SSI was $1.74 \%$ among patients undergoing orthopaedic surgeries in this study. Jain et al., (2013) have reported $22.58 \%$ of SSI in their study in Bhopal. In the present study, rate of post-operative wound infection was least $(0.42 \%)$ in operations conducted in department of general surgery. Incidence of $5 \%, 11.7 \%$ and $39 \%$ has been reported by Sahu et al., (2009), Maheshwari et al., (2013) from Meerut and Apanga et al., (2014) from Ghana.

There may be inappropriate recording of incidence of post-operative wound infection because all patients who developed postoperative wound infection may not have approached our hospital.

\section{Gender distribution (Table 2)}

There were a total of 35 males and 47 females in our study, the ratio of male to female being
1:1.34. Male to female ratio was $4: 1$ in orthopaedic patients and 1:1.33 in patients admitted under general surgery.

\section{Age distribution (Figure 1)}

Amongst the patients with post-operative wound infection, the incidence was higher in the age group of $>48$ years $(35.37 \%)$ followed by $38-47$ years $(30.44 \%), 28-37$ years $(24.39 \%)$ and $18-27$ years $(12.9 \%)$. In this study age $>48$ years was found to be a risk factor for developing SSI. Ahmed M et al., (2007), Bandaru et al., (2012), Saxena et al., (2013) have also stated that age $>50$ years is a risk factor for developing SSI. We also noticed that number of post-operative wound infection increased as the age increased. Mahesh CB et al., (2010) have observed a similar finding in their study. Higher incidence of post-operative wound infection in the elderly age group may be attributed to malabsorption, malnutrition, low healing rate, low immunity, underlying chronic disorders.

\section{Risk factors (Table 3)}

We found Diabetes Mellitus and advancing age as risk factors among patients who developed post-operative wound infection. Razavi et al., (2005), Ahmed et al., (2007) and Apanga et al., (2014) have also noted a similar finding in their study. Hyperglycaemia has deleterious effects on host immune function especially on function of neutrophils. Poor control of glucose during surgery and in the peri operative period increases the risk of infection and worsens outcome from sepsis.

We also observed multiparty as the risk factor in 28 of $35(80 \%)$ obstetrics and gynaecology patients. Bhadauria et al., (2013) and Rahman et al., (2011) have also stated a similar finding. This may be attributed to malnutrition and anaemia due to repeated child birth. 


\section{Type of surgeries conducted (Table 4)}

Fracture repair was associated with highest number of post-operative wound infections (38 out of 82) followed by abdominal hysterectomy (29.27\%), emergency Caesarean section (10.98\%). Modified radical mastectomy and inguinal hernia repair constituted $2.44 \%$ each. Rest of the operative procedures constituted for $1.22 \%$ of postoperative wound infections (Total hip replacement, Total knee replacement, Elective LSCS, Postpartum sterilization, Laparoscopic appendicectomy, Open appendicectomy, Laparoscopic adhesiolysis and appendicectomy).

Post-operative wound infections among elective and emergency surgeries (Table 5)

In the present study elective surgeries were associated with higher number of postoperative wound infections (56.1\%) when compared to emergency surgeries (43.9\%). In our study risk factors were more in patients who underwent Obstetrics and Gynaecological surgeries. This may have contributed to increased incidence of postoperative wound infections in elective surgeries than in emergency surgeries.

However the rate of infection was found to be more in emergency surgeries than elective surgeries among patients who underwent surgery in the department of Orthopaedics and General surgery. Patel et al., (2012) reported higher infection rate in patients who underwent emergency surgeries than elective surgeries because emergency surgeries are more often involved with complications and more number of dirty cases. Shahane et al., (2012) reported a higher SSI rate in elective surgeries $(7.9 \%)$ when compared to emergency surgeries $(2.7 \%)$.

\section{Time of presentation of SSI (Table 6)}

More than half of the patients presented with post-operative wound infection in the postoperative period of 3-10 days $(53.66 \%)$ followed by 11-30days (21.95\%), 31-60 days (12.12\%), >3 months-6months (4.88\%), >6 months-1year (3.66\%), 61-90 days (2.44\%). Only one patient presented on post-operative day 2 with SSI. When considering the new guidelines of surgical site infections by CDC (2015), 7 cases that presented after 90 days will have to be excluded.

Since CDC 1999 guidelines were available during the study period, the data of patients who presented with SSI after 90 days has been included and analysed.

Majority of the Obstetrics and gynaecological patients (28 out of 35) had SSI in the postoperative period of 3-10 days, the data was further divided and analysed. It was observed that 9 among them (32.14\%) presented with SSI on post-operative day (POD) 8 followed by $17.86 \%$ on POD 9; $14.29 \%$ on POD 5, 7 and $10 ; 7.14 \%$ on POD 6. Rahman et al., (2011) also noticed that majority of their patients (52\%) presented with SSI during the post-operative period of 6-10 days. Bhadauria et al., (2013) reported that majority of the patients presented with SSI after 4 days of operation. Our finding indicates that the source of infection was mainly from the patients, wards, surroundings, attendants etc. 
Table.1 Incidence

\begin{tabular}{|c||c||c|}
\hline & $\begin{array}{c}\text { Total number of } \\
\text { surgeries performed }\end{array}$ & $\begin{array}{c}\text { Total number of } \\
\text { cases infected }\end{array}$ \\
\hline \hline ORTHO & 2290 & $40(1.74 \%)$ \\
\hline OBG & 873 & $35(4.01 \%)$ \\
\hline SURGERY & 1666 & $07(0.42 \%)$ \\
\hline \hline Total & $\mathbf{4 8 2 9}$ & $\mathbf{8 2}(\mathbf{1 . 7 0 \%})$ \\
\hline
\end{tabular}

Table.2 Gender distribution

\begin{tabular}{|l|l|l|l|}
\hline & MALE & FEMALE & TOTAL \\
\hline \hline ORTHO & 32 & 08 & 40 \\
\hline OBG & - & 35 & 35 \\
\hline SURGERY & 03 & 04 & 07 \\
\hline \hline TOTAL & 35 & 47 & 82 \\
\hline
\end{tabular}

Table.3 Risk factors

\begin{tabular}{||c||c|c|c||c|c||}
\hline $\begin{array}{c}\text { Risk factors / } \\
\text { Department }\end{array}$ & $\begin{array}{c}\text { ORTHO } \\
(\mathrm{n}=40)\end{array}$ & $\begin{array}{c}\text { OBG } \\
(\mathrm{n}=35)\end{array}$ & $\begin{array}{c}\text { SURGERY } \\
(\mathrm{n}=07)\end{array}$ & $\begin{array}{c}\text { TOTAL } \\
(\mathrm{n}=82)\end{array}$ & Percentage \\
\hline \hline Diabetes Mellitus & 09 & 05 & 01 & 15 & $18.29 \%$ \\
\hline Hypertension & 03 & 01 & 01 & 05 & $6.10 \%$ \\
\hline Advanced age & 16 & 09 & 04 & 29 & $35.37 \%$ \\
\hline
\end{tabular}

Table.4 Type of surgeries conducted

\begin{tabular}{|c|c|c|}
\hline Department & Type of surgery & Number (\%) \\
\hline \multirow{3}{*}{$\begin{array}{l}\text { Orthopaedics } \\
(\mathrm{n}=40)\end{array}$} & Fracture repair & $38(73.08 \%)$ \\
\hline & Total hip replacement & $01(1.22 \%)$ \\
\hline & Total knee replacement & $01(1.22 \%)$ \\
\hline \multirow{4}{*}{$\begin{array}{l}\text { Obstetrics and Gynaecology } \\
(\mathrm{n}=35)\end{array}$} & Elective LSCS & $01(1.22 \%)$ \\
\hline & Emergency LSCS & $09(10.98 \%)$ \\
\hline & Abdominal hysterectomy & $24(29.27 \%)$ \\
\hline & Post-partum sterilization & $01(1.22 \%)$ \\
\hline \multirow{6}{*}{$\begin{array}{l}\text { Surgery } \\
(\mathrm{n}=07)\end{array}$} & Laparoscopic appendicectomy & $01(1.22 \%)$ \\
\hline & Open appendectomy & $01(1.22 \%)$ \\
\hline & Modified radical mastectomy & $02(2.44 \%)$ \\
\hline & Inguinal hernia repair & $02(2.44 \%)$ \\
\hline & Laparoscopic adhesiolysis and appendicectomy & $01(1.22 \%)$ \\
\hline & TOTAL & 82 \\
\hline
\end{tabular}

Table.5 Post-operative wound infections in emergency and elective surgeries

\begin{tabular}{|c||c|c|c|}
\hline & Emergency & Elective & Total \\
\hline \hline ORTHO & 23 & 17 & 40 \\
\hline OBG & 09 & 26 & 35 \\
\hline SURGERY & 04 & 03 & 07 \\
\hline \hline $\begin{array}{c}\text { TOTAL } \\
(\mathrm{n}, \boldsymbol{\%})\end{array}$ & $\mathbf{3 6}(\mathbf{4 3 . 9 0 \% )}$ & $\mathbf{4 6} \mathbf{( 5 6 . 1 0 \% )}$ & $82(100 \%)$ \\
\hline
\end{tabular}


Table.6 Time of presentation

\begin{tabular}{|c|c|c|c|c|c|c|}
\hline \multirow{3}{*}{$\begin{array}{c}\text { Time of } \\
\text { presentation }\end{array}$} & \multicolumn{6}{|c|}{ Number of cases } \\
\hline & \multicolumn{2}{|c|}{ ORTHO } & \multirow{2}{*}{ OBG } & \multirow{2}{*}{ SURGERY } & \multicolumn{2}{|c|}{ TOTAL $(\mathbf{n}, \%)$} \\
\hline & $\begin{array}{l}\text { According to } \\
1999 \text { CDC } \\
\text { guidelines }\end{array}$ & $\begin{array}{l}\text { According to } \\
2015 \text { CDC } \\
\text { guidelines }\end{array}$ & & & $\begin{array}{l}\text { According to } \\
1999 \text { CDC } \\
\text { guidelines }\end{array}$ & $\begin{array}{l}\text { According to } \\
2015 \text { CDC } \\
\text { guidelines }\end{array}$ \\
\hline$<3$ days & 01 & 01 & - & - & $01(1.22 \%)$ & 01 \\
\hline 3-10 days & 12 & 12 & 28 & 04 & $44(53.66 \%)$ & 44 \\
\hline 11-30 days & 08 & 08 & 07 & 03 & $18(21.95 \%)$ & 18 \\
\hline 31-60 days & 10 & 10 & - & - & $10(12.12 \%)$ & 10 \\
\hline 61-90 days & 02 & 02 & - & - & $02(2.44 \%)$ & 02 \\
\hline $\begin{array}{l}>3 \text { months- } \\
6 \text { months }\end{array}$ & 04 & - & - & - & $04(4.88 \%)$ & - \\
\hline$>6$ months-1year & 03 & - & - & - & $03(3.66 \%)$ & - \\
\hline TOTAL & 40 & 33 & 35 & 07 & $82(100 \%)$ & 75 \\
\hline
\end{tabular}

Table.7 Presenting symptoms

\begin{tabular}{|c|c|c|c|c|c|c|c|}
\hline Symptoms & \multicolumn{2}{|c|}{ ORTHO $(\mathrm{n}=40)$} & \multicolumn{2}{|c|}{ OBG $(\mathrm{n}=35)$} & \multicolumn{2}{c|}{ SURGERY (n=7) } & $\begin{array}{c}\text { TOTAL } \\
(\mathrm{n}=82)\end{array}$ \\
\cline { 2 - 8 } & Number & $\%$ & Number & $\%$ & Number & $\%$ & $\mathrm{n}, \%$ \\
\hline Fever & 10 & $25 \%$ & 7 & $20 \%$ & 02 & $28.57 \%$ & $\begin{array}{c}19 \\
(23.17 \%)\end{array}$ \\
\hline $\begin{array}{c}\text { Purulent } \\
\text { Discharge }\end{array}$ & 35 & $87.5 \%$ & 24 & $68.57 \%$ & 03 & $42.86 \%$ & $\begin{array}{c}\mathbf{6 2} \\
\mathbf{7 5 . 6 1 \%})\end{array}$ \\
\hline $\begin{array}{c}\text { Wound } \\
\text { gaping }\end{array}$ & 05 & $12.5 \%$ & 08 & $22.86 \%$ & 01 & $14.29 \%$ & $\begin{array}{c}14 \\
(17.07 \%)\end{array}$ \\
\hline $\begin{array}{c}\text { Pain and } \\
\text { tenderness }\end{array}$ & 21 & $52.5 \%$ & 09 & $25.71 \%$ & 04 & $57.14 \%$ & $\begin{array}{c}34 \\
(41.46 \%)\end{array}$ \\
\hline
\end{tabular}

Table.8 Aerobic bacterial profile of post-operative wound infection

\begin{tabular}{|c|c|c|c|c|}
\hline Organisms isolated & ORTHO & OBG & SUREGRY & $\begin{array}{c}\text { TOTAL } \\
(\mathrm{n}, \%)\end{array}$ \\
\hline \hline Staphylococcus aureus & 17 & 17 & 02 & $36(73.47 \%)$ \\
\hline Escherichia coli & - & 03 & 03 & $06(12.24 \%)$ \\
\hline Klebsiella pneumoniae & 03 & - & - & $03(6.12 \%)$ \\
\hline Pseudomonas aeruginosa & 01 & 01 & - & $02(4.08 \%)$ \\
\hline $\begin{array}{c}\text { Proteus mirabilis } \\
\text { Klebsiella } \text { pneumoniae } \\
\text { Escherichia coli }\end{array}$ & - & 01 & - & $01(2.04 \%)$ \\
\hline TOTAL & 22 & - & - & $01(2.04 \%)$ \\
\hline
\end{tabular}


Table.9 Antibiotic susceptibility pattern of Staphylococcus aureus

\begin{tabular}{|c|c|c|c|c|}
\hline \hline Antibiotics & $\begin{array}{c}\text { ORTHO } \\
\mathrm{n}=17\end{array}$ & $\begin{array}{c}\text { OBG } \\
\mathrm{n}=17\end{array}$ & $\begin{array}{c}\text { SURGERY } \\
\mathrm{n}=02\end{array}$ & $\begin{array}{c}\text { TOTAL } \\
\mathrm{n}=36\end{array}$ \\
\hline \hline $\mathrm{P}$ & $5.88 \%$ & $5.88 \%$ & 0 & $5.55 \%$ \\
\hline GEN & $76.47 \%$ & $70.59 \%$ & $50 \%$ & $72.22 \%$ \\
\hline $\mathrm{E}$ & $52.94 \%$ & $58.82 \%$ & 0 & $52.78 \%$ \\
\hline $\mathrm{CD}$ & $76.47 \%$ & $76.47 \%$ & 0 & $72.22 \%$ \\
\hline $\mathrm{TE}$ & $64.71 \%$ & $88.24 \%$ & $100 \%$ & $77.78 \%$ \\
\hline $\mathrm{CIP}$ & $29.41 \%$ & $41.18 \%$ & 0 & $33.33 \%$ \\
\hline $\mathrm{COT}$ & $76.47 \%$ & $70.59 \%$ & $50 \%$ & $72.22 \%$ \\
\hline $\mathrm{C}$ & $88.24 \%$ & $94.12 \%$ & $100 \%$ & $91.67 \%$ \\
\hline LZ & $100 \%$ & $100 \%$ & $100 \%$ & $\mathbf{1 0 0 \%}$ \\
\hline $\mathrm{VA}$ & $100 \%$ & $100 \%$ & $100 \%$ & $\mathbf{1 0 0 \%}$ \\
\hline
\end{tabular}

P-Penicillin, GEN-Gentamicin, E-Erythromycin, CD-Clindamycin, TE-Tetracycline, CIP-Ciprofloxacin, COTCotrimoxazole, C-Chloramphenicol, LZ-Linezolid, VA-Vancomycin

Table.10 Antibiotic susceptibility pattern of Enterobacteriaceae

\begin{tabular}{|c|c|c|c|}
\hline Antibiotics & $\begin{array}{c}\text { Escherichia } \\
\text { coli } \\
\mathrm{n}=07\end{array}$ & $\begin{array}{c}\text { K. pneumoniae } \\
\mathrm{n}=04\end{array}$ & $\begin{array}{c}\text { P. mirabilis } \\
\mathrm{n}=01\end{array}$ \\
\hline \hline Amikacin & $71.42 \%$ & $50 \%$ & $100 \%$ \\
\hline Gentamicin & $28.57 \%$ & $25 \%$ & $100 \%$ \\
\hline Ceftazidime & $14.29 \%$ & $25 \%$ & $100 \%$ \\
\hline Ceftriaxone & $14.29 \%$ & $25 \%$ & $100 \%$ \\
\hline Cefotaxime & $14.29 \%$ & $25 \%$ & $100 \%$ \\
\hline Cefipime & $14.29 \%$ & $25 \%$ & $100 \%$ \\
\hline Imipenem & $\mathbf{1 0 0 \%}$ & $\mathbf{1 0 0 \%}$ & - \\
\hline Meropenem & $\mathbf{1 0 0 \%}$ & $\mathbf{1 0 0 \%}$ & $100 \%$ \\
\hline Piperacillin-tazobactam & $\mathbf{1 0 0 \%}$ & $\mathbf{1 0 0 \%}$ & $100 \%$ \\
\hline Ciprofloxacin & $14.29 \%$ & $25 \%$ & $100 \%$ \\
\hline Levofloxacin & $28.57 \%$ & $25 \%$ & $100 \%$ \\
\hline Cotrimoxazole & $14.29 \%$ & $\mathbf{1 0 0 \%}$ & $100 \%$ \\
\hline Chloramphenicol & $57.14 \%$ & $\mathbf{1 0 0 \%}$ & $100 \%$ \\
\hline
\end{tabular}


Table.11 ESBL producers

\begin{tabular}{||c||c|c|c||}
\hline Organisms & $\begin{array}{c}\text { Total number of } \\
\text { isolates }\end{array}$ & ESBL producers & Percentage \\
\hline \hline Escherichia coli & 07 & 06 & $85.71 \%$ \\
\hline Klebsiella pneumoniae & 04 & 03 & $75 \%$ \\
\hline \hline TOTAL & 12 & 09 & $75 \%$ \\
\hline
\end{tabular}

Total: 09 out of 12 Enterobacteriaceae (75\%); Escherichia coli: 06 (66.67\%); Klebsiella pneumoniae: 03 (33.33\%)

Table.12 Antibiotic susceptibility pattern of Pseudomonas aeruginosa

\begin{tabular}{|c|c|}
\hline Antibiotics & $\begin{array}{c}\text { Pseudomonas aeruginosa } \\
(\mathrm{n}=02)\end{array}$ \\
\hline \hline Amikacin & $100 \%$ \\
\hline Gentamicin & $100 \%$ \\
\hline Tobramycin & $100 \%$ \\
\hline Ceftazidime & $100 \%$ \\
\hline Cefipime & $100 \%$ \\
\hline Imipenem & $100 \%$ \\
\hline Meropenem & $100 \%$ \\
\hline Piperacillin-tazobactam & $100 \%$ \\
\hline Ciprofloxacin & $100 \%$ \\
\hline Levofloxacin & $100 \%$ \\
\hline
\end{tabular}

Fig.1 Age Distribution

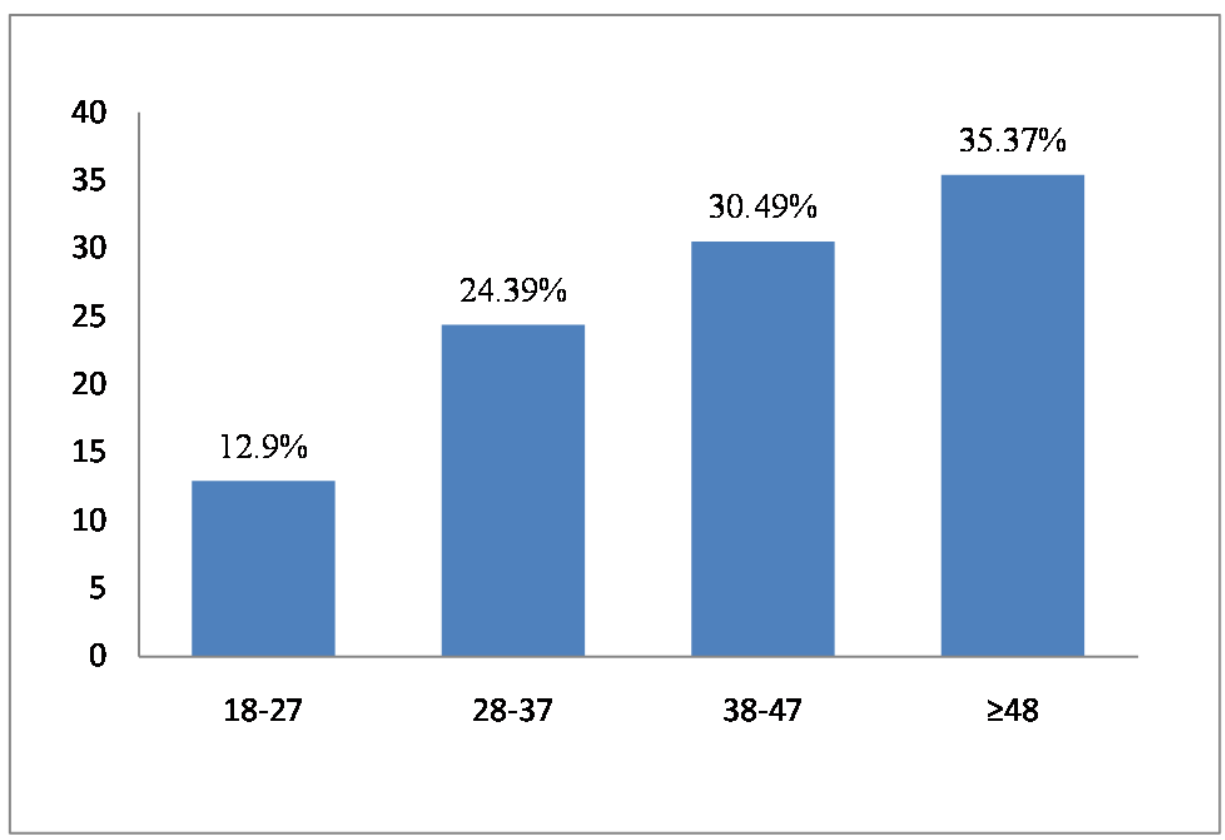


Fig.2 Presenting symptoms

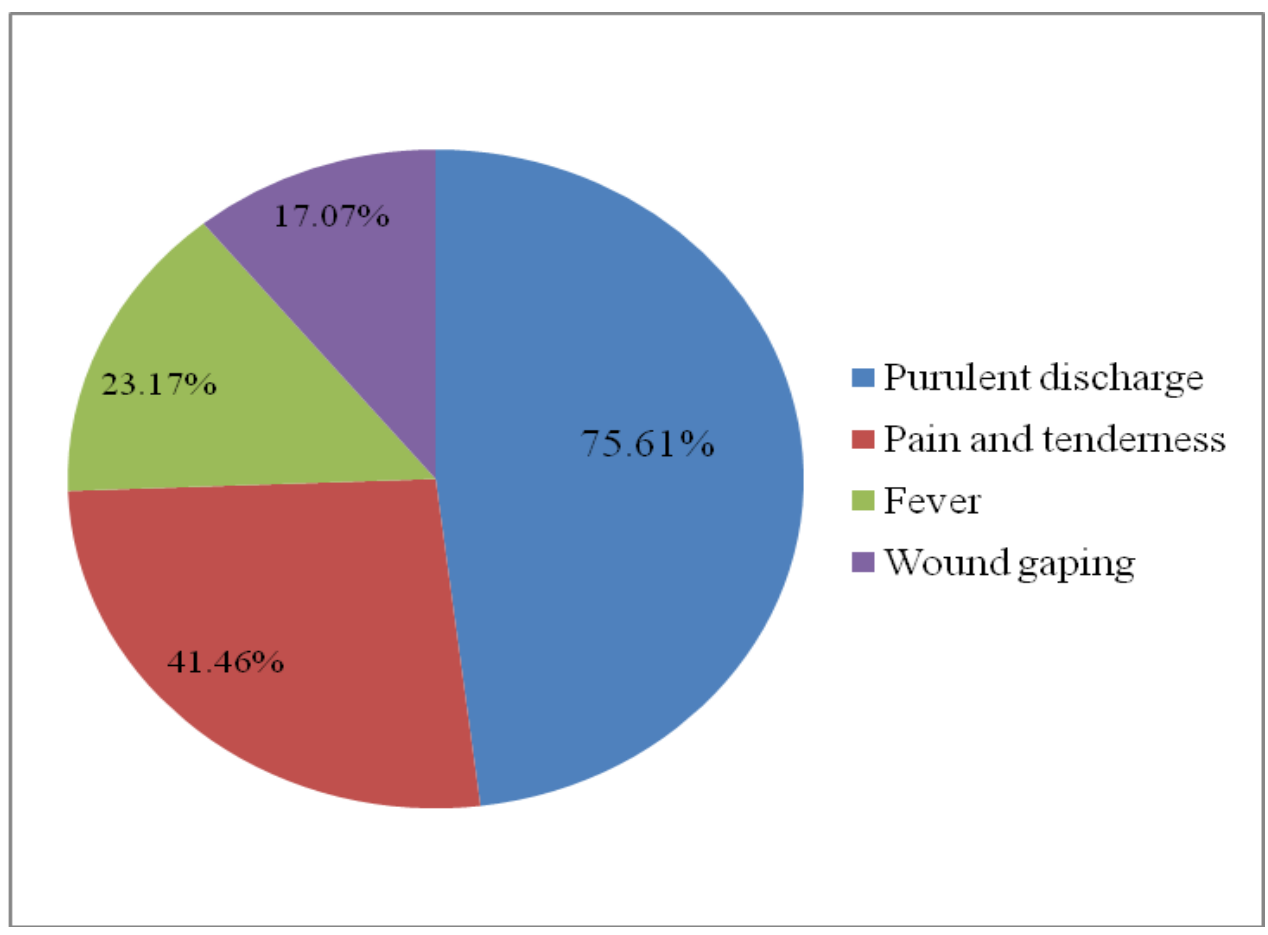

Fig.3 Correlation of Gram stain and culture

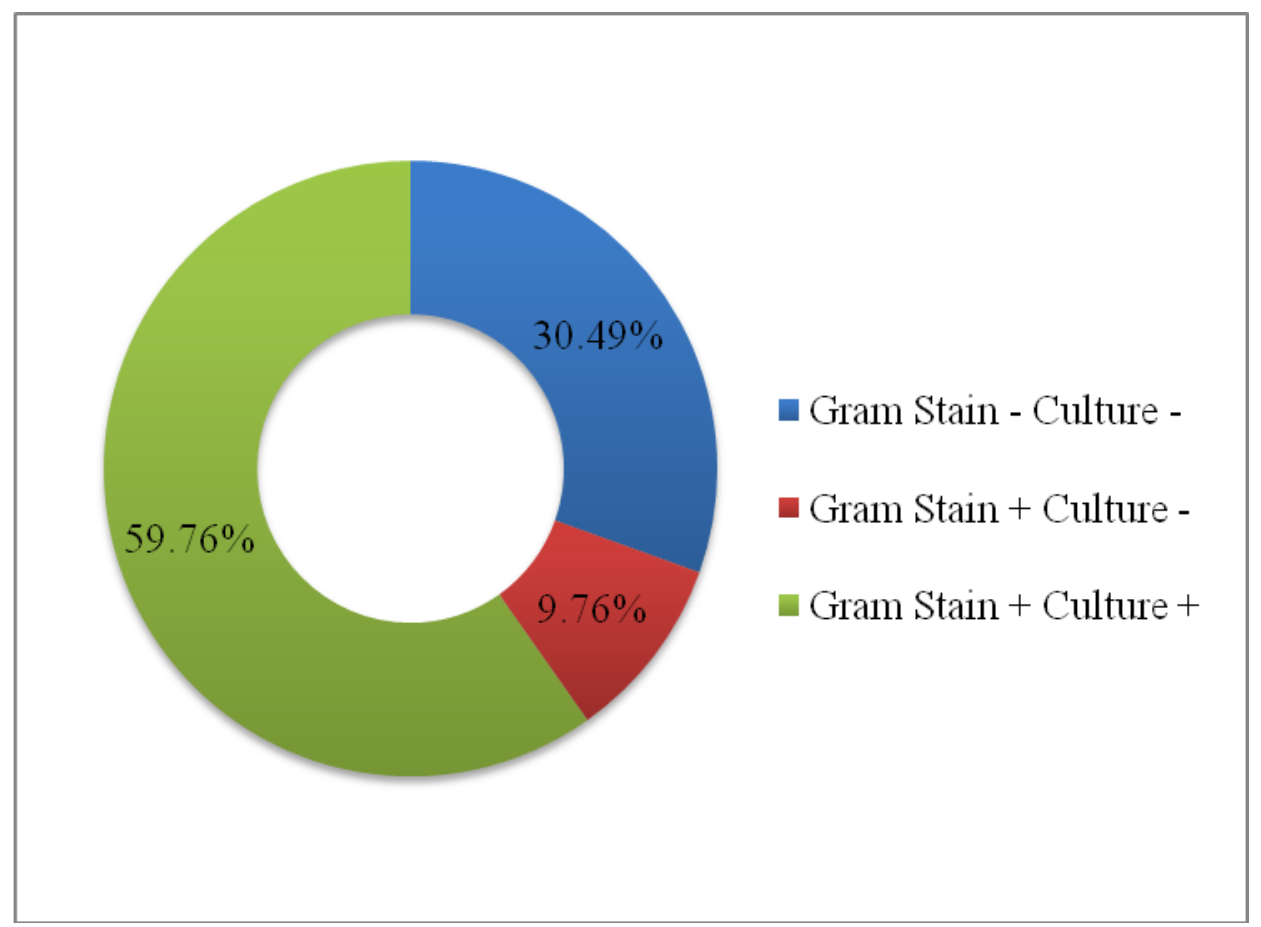


Fig.4 Aerobic bacterial profile of post-operative wound infection

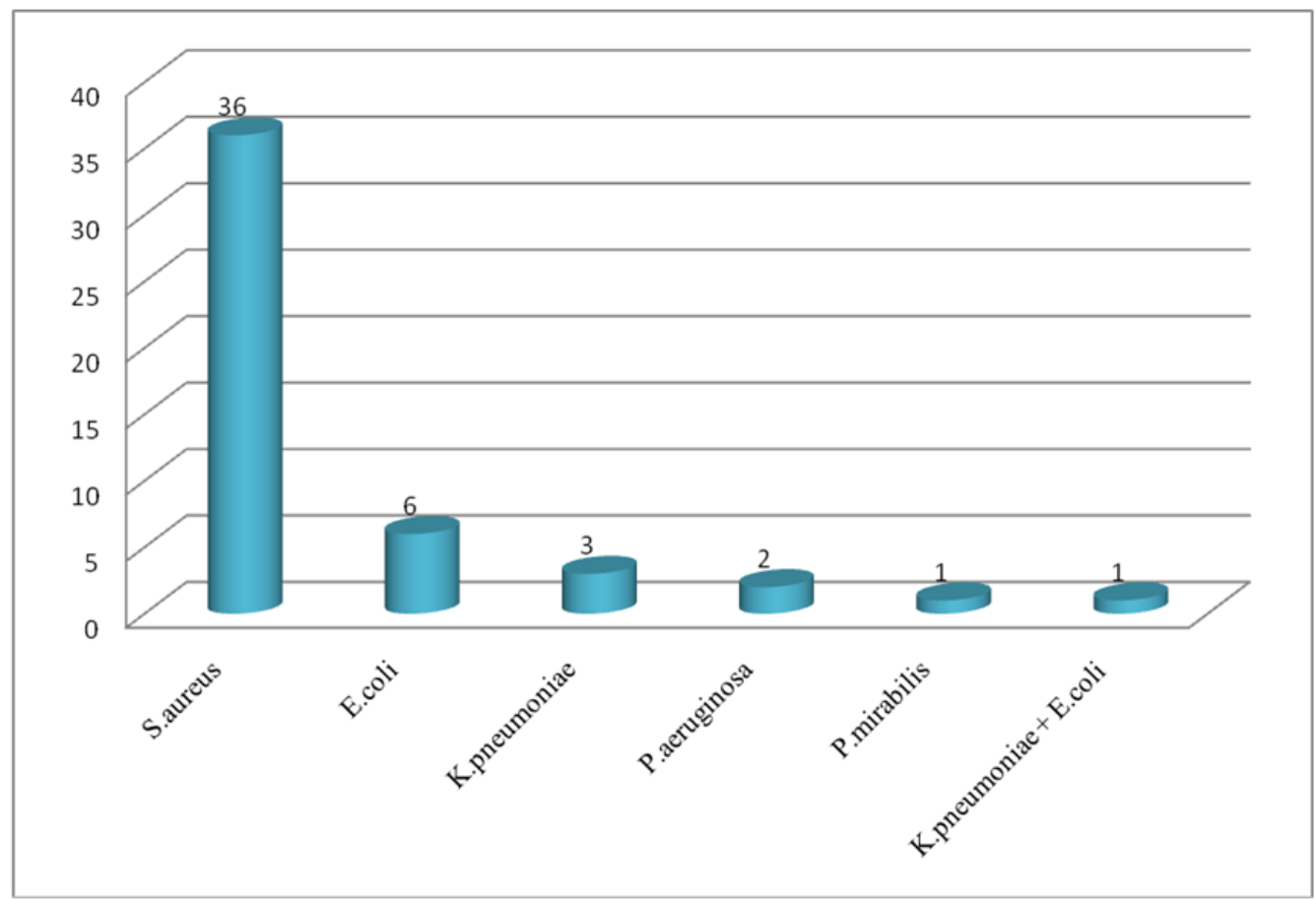

Fig.5 Comparison of antibiotic sensitivity pattern of MSSA and MRSA

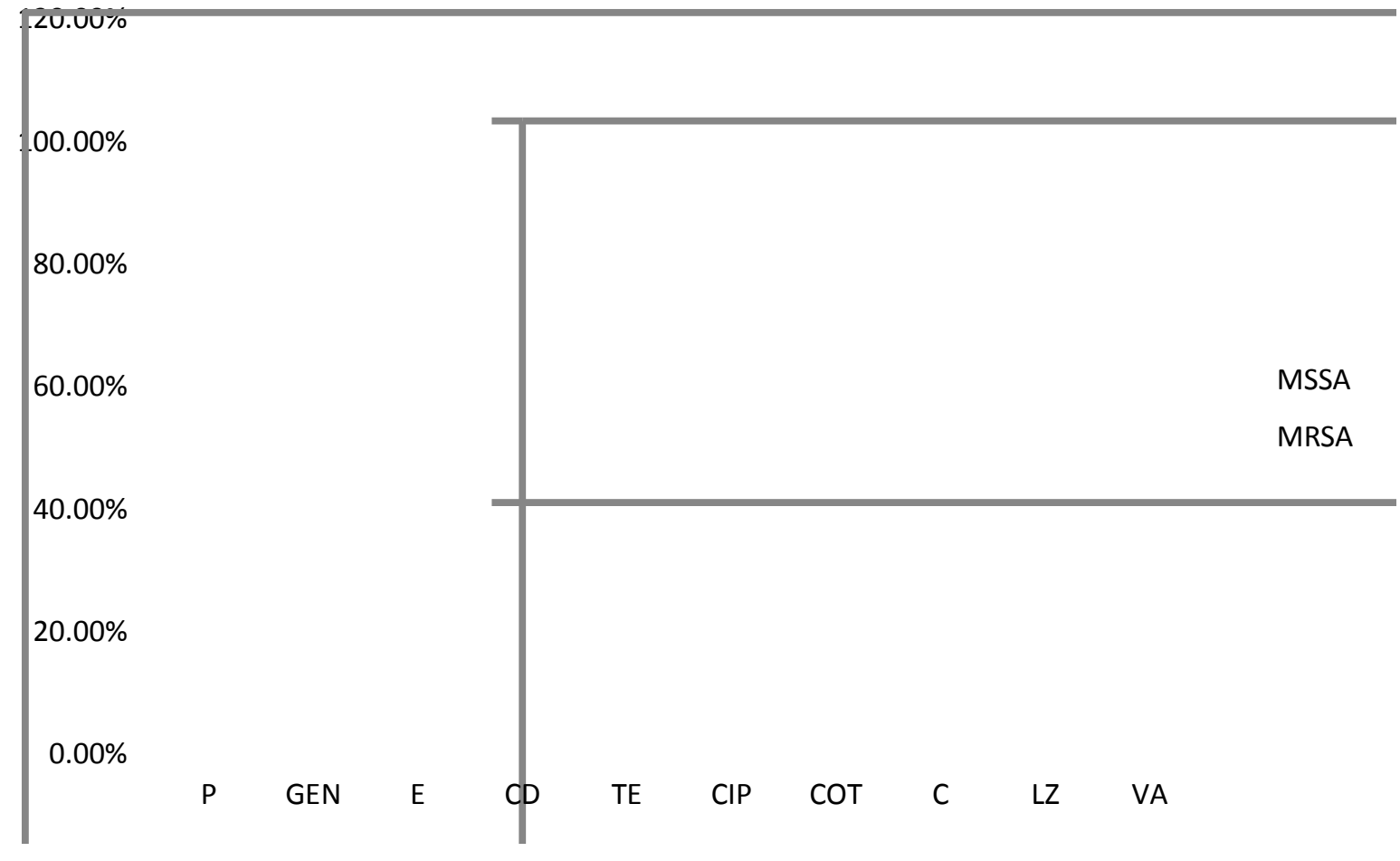


Fig.6 Antibiotic susceptibility pattern of E. coli and K. pneumoniae

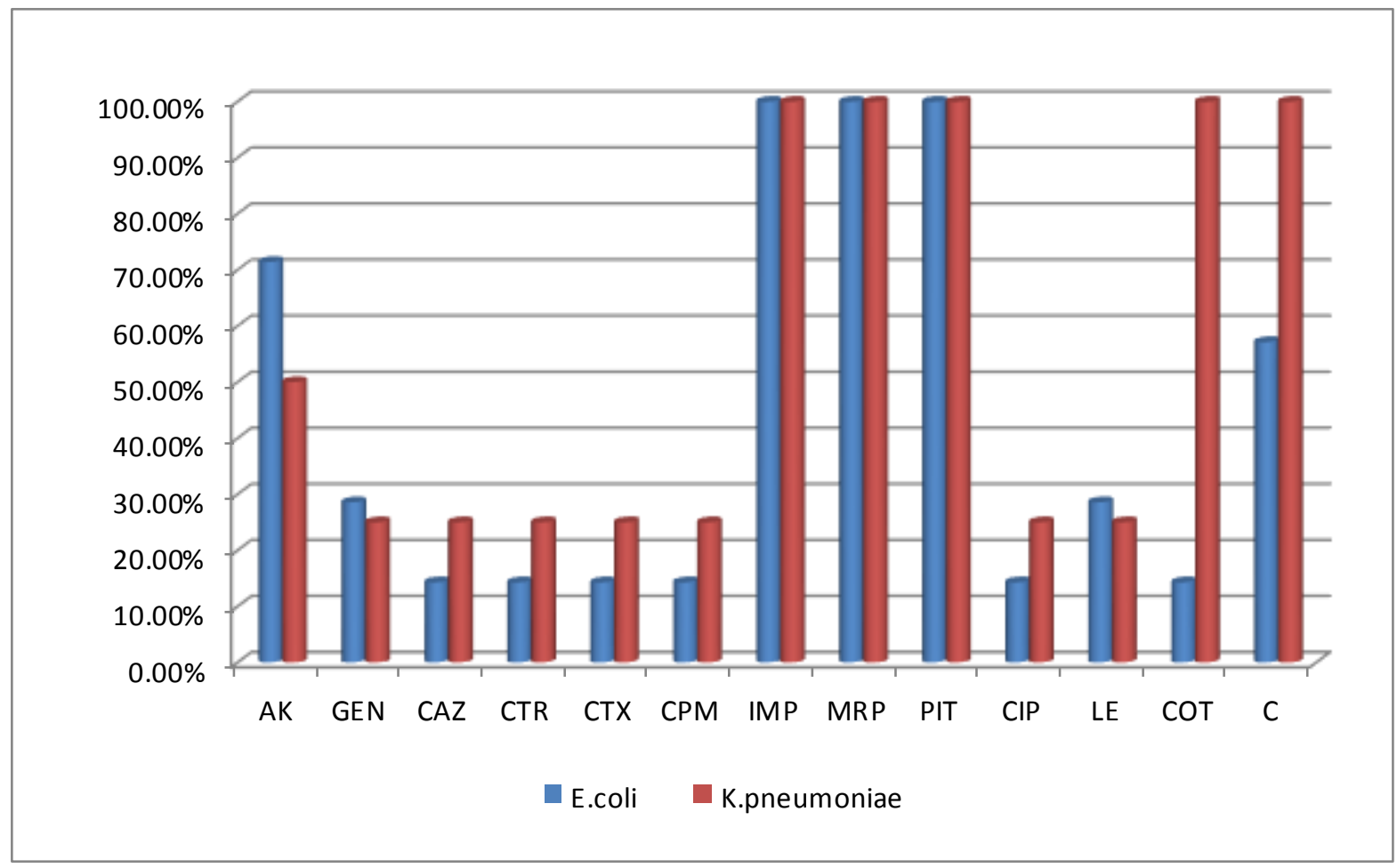

Presenting symptoms (Table 7, Figure 2)

The most common presenting symptom in this study was purulent discharge $(75.61 \%)$ followed by pain and tenderness $(41.46 \%)$, fever $(23.17 \%)$ and wound gaping (17.07\%).

\section{Correlation of Gram stain and culture (Figure 3)}

More than half of the samples $(59.76 \%)$ showed organisms in Gram Stain and in culture as well. $30.49 \%$ samples had no organisms in Gram stain and had no growth on aerobic culture. Our finding on culture positivity is similar to studies by Rahman et al., (2011) and Ramesh et al., (2012) who reported $65 \%$ and $66 \%$ culture positivity respectively. In the present study it was noticed that some patients were already receiving antibiotic therapy even before the sample was sent for culture. This might have led to the absence of organisms in Gram Stain and culture. A small percentage $(9.76 \%)$ of the samples showed organisms in the smear which did not grow. The reason for this may be the presence of anaerobes which could not have grown on aerobic culture.

Aerobic bacterial profile and antibiotic sensitivity pattern (Table 8, Figure 4)

A total of 49 samples showed growth on aerobic culture. Among these Staphylococcus aureus was the predominant isolate (36 out of 49) accounting for $73.47 \%$. This finding of Staphylococcal predominance is similar to other studies by Gupta (2012), Ramesh et al., (2012), and Khosravi et al., (2009). Proportion of MRSA in the present study was $77.78 \%$. Over $75 \%$ of $S$. aureus were Methicillin resistant in studies by Gupta (2012), Mahesh et al., (2010) and Golia et al., (2014). Majority of S. aureus were isolated 
from orthopaedic and gynaecological surgeries in our study. All the Staphylococcus aureus isolates showed $100 \%$ susceptibility to Linezolid and Vancomycin (Table 9). This finding is supported by Rao et al., (2013), Shahane et al., (2012) and Ranjan et al., (2013). Over $70 \%$ of the isolates were sensitive to Gentamicin, clindamycin, tetracycline and cotrimoxazole. Out of 10 Clindamycin resistant isolates, 3 showed inducible resistance (D test positive). All the three isolates were Methicillin sensitive.

When we compared the sensitivity patterns of MSSA and MRSA (Figure 5), we noticed that both showed maximum susceptibility to Linezolid and Vancomycin (100\%) followed by Chloramphenicol $(92.86 \%$ for MSSA and $87.5 \%$ for MRSA). Majority of MSSA were sensitive to erythromycin and clindamycin $(64.29 \%$ and $89.29 \%$ respectively) whereas only $12.5 \%$ of MRSA were sensitive to these drugs. This finding of MRSA isolates being more drug resistant than MSSA is supported by Ranjan et al., (2013). Wassef et al., (2012) have also reported co-resistance of MRSA to tetracycline, clindamycin and Gentamicin in their study.

Escherichia coli was the second most common organism isolated in this study. Rahman et al., (2011), Sonawane et al., (2010) and Mawalla et al., (2011) also reported a similar finding. Maximum (100\%) susceptibility was seen against Piperacillintazobactam, Imipenem and Meropenem followed by Amikacin (71.42\%) and Chloramphenicol (57.14\%). Least susceptibility was observed against Gentamicin and Levofloxacin (28.57\% each); cephalosporins, ciprofloxacin and Cotrimoxazole (14.29\% each) (Table 10). Similar antibiotic sensitivity pattern has been reported by Sonawane et al., (2010), Shah et al., (2015) and Golia et al., (2014).
Klebsiella pneumoniae was the third most common organism isolated accounting for $6.12 \%$.. This organism showed $100 \%$ susceptibility to Cotrimoxazole, Chloramphenicol, Piperacillin-tazobactam, Imipenem and Meropenem (Table 10, Figure 6). Only about a half of the isolates were sensitive to Amikacin. Like $E$. coli, $K$. pneumoniae also showed least susceptibility against cephalosporins, Gentamicin, ciprofloxacin and Levofloxacin (25\% each). $75 \%$ of all isolates showed ESBL production. Sonawane et al., (2010) have reported a similar finding of antibiotic susceptibility pattern. However Verma et al., (2012) reported maximum susceptibility towards ceftriaxone $(66.67 \%)$ in their study.

\section{ESBL producers (Table 11)}

ESBL production was seen in 9 of the 12 Enterobacteriaceae isolated accounting for 75\%. Among these, 6 were E. coli and 3 were $K$. pneumoniae $(66.67 \%$ and $33.33 \%$ respectively). Over $60 \%$ of ESBL production has been noted by Shanthi et al., (2012), Wassef et al., (2012) and Mawalla et al., (2011).

There were 2 isolates of $P$. aeruginosa in the present studies which were $100 \%$ susceptible to all the antibiotics tested (Table 12). Over $83 \%$ susceptibility against Piperacillintazobactam, Ceftazidime and Imipenem has been reported by Shahane et al., (2012). Sonawane et al., (2010) also reported 80-90\% sensitivity of $P$. aeruginosa against Piperacillin-tazobactam and Imipenem and higher percentage of resistance to all the other antibiotics tested.

Overall incidence of post-operative wound infections in the present study was $1.7 \%$. The risk factors associated were Diabetes mellitus, hypertension, advanced age and multiparty. $S$. aureus was the predominant isolate followed 
by $E$. coli, $K$. pneumoniae, $P$. aeruginosa and P. mirabilis. $22.22 \%$ of $S$. aureus were Methicillin resistant and also showed coresistance to many of the commonly used antibiotics. Among the Enterobacteriaceae isolated, more than half of them were ESBL producers.

Reduction in the rate of post-operative wound infection is necessary to bring down the morbidity and mortality associated with it as well as to lower the wastage of healthcare resources, treatment cost and economical burden on the patient. Adequate glycaemic control in diabetic patients, proper antimicrobial prophylaxis, infection control measures, suitable antibiotic policy development, and surveillance are the most effective measures to reduce post-operative wound infections as well as emergence of multidrug resistant strains.

\section{Funding}

This research received no specific grant from any funding agency in the public, commercial, or not- for-profit sectors.

\section{References}

Ahmed, M., Alam SM, Khan O, Manzar S. Post-operative wound infection: A surgeons dilemma. Pakistan Journal of Surgery. 2007; 23(01): 41-46.

Apanga, S., Adda J, Issahaku M, Amofa J, Mawufemor KRA, Bugri S. Postoperative surgical site infection in a surgical ward of a tertiary care hospital in Northern Ghana. Int J Res Health Sci., 2014; 02(01):207-12.

Bandaru, N.R., Ranga Rao A, Vijayananda Prasad K, Murty R. A prospective study of postoperative wound infections in a teaching hospital of rural setup. Journal of Clinical and Diagnostic Research. 2012; 06(07): 1266-71.
Bangal, V.B., Borawake SK, Shinde KK, Gavhane SP. Study of surgical site infections following gynaecological surgery at tertiary care teaching hospital in Rural India. International Journal of Biomedical Research. 2014; 05(02): 113-16.

Barie, P.S., Surgical Infections and Antibiotic Use. In: Courtney M. Townsend, editor. Sabiston Textbook of Surgery: The Biological Basis of Modern Surgical Practice, $19^{\text {th }}$ ed. New Delhi: Elsevier; 2012. Pp. 240-280.

Beilman, G.J., Dunn DL. Surgical infections. In: F.Charles Brunicardi, editor. Schwartz's Principles of Surgery, $10^{\text {th }}$ ed. United States: McGraw-Hill Education; 2015. Pp. 135-160.

Bhadauria, A.R., Hariharan C. Clinical study of post-operative wound infections in obstetrics and gynaecological surgeries in a tertiary care setup. Int J Reprod Contracept Obstet Gynecol. 2013; 02(04): 631-38.

Bibi, S., Channa GA, Siddiqui TR, Ahmed W. Pattern of bacterial pathogens in postoperative wounds and their sensitivity patterns. Journal of Surgery Pakistan (International). 2012; 17(04): 164-67.

CLSI. Performance Standards for Antimicrobial Susceptibility Testing; Twenty-Fourth Informational Supplement. CLSI document M100S24. Wayne, PA: Clinical and Laboratory Standards Institute; 2014.

Devjani De, Saxena S, Mehta G, Yadav R, Dutta R. Risk factor analysis and microbial etiology of surgical site infections following lower segment Caesarean section. International Journal of Antibiotics. 2013;1-6.

Golia, S., Asha S, Kamath B, Nirmala AR. A study of superficial surgical site infections in a tertiary care hospital at Bangalore. International Journal of 
Research in Medical Sciences. 2014; 02(02): 647-52.

Gupta, P.A. Study of postoperative wound infection among post surgical patients at Calicut medical college, Kerala, India. Journal of Evolution of Medical and Dental Sciences. 2012; 01(04): 582-88.

Jain, B.K., Banerjee M. Surgical site infections and its risk factors in orthopaedics: A prospective study in teaching hospital of Central India. Int $J$ Res Med. 2013; 02(01);110-113.

Khosravi, A.D., Ahmadi F, Salmanzadeh S, Dashtbozorg A, Montazeri EA. Study of bacteria isolated from orthopaedic implant infections and their antibiotic susceptibility pattern. Research journal of microbiology. 2009; 4(4): 158-163.

Kitembo, S.K., Chugulu SG. Incidence of surgical site infections and microbial pattern at Kilimanjaro Christian Medical Centre. The Annals of African Surgery. 2013; 10(01): 26-31.

Korol, E., Johnston K, Waser N, Sifakis F, Jafri HS, et al., A systematic review of risk factors associated with surgical site infections among surgical patients. PLoS ONE. 2013;8(12):e83743:1-7.

Mahesh, C.B., Shivakumar S, Suresh BS, Chidanand SP, Vishwanath Y. A prospective study of surgical site infections in a teaching hospital. Journal of Clinical and Diagnostic Research. 2010; (04):3114-19.

Maheshwari, M.K., Pandey S, Bhatnagar AK, Agrawal A. A prospective study of surgical site infection in elective and emergency abdominal surgery in $\mathrm{CSSH}$, Meerut. Journal of Advance Researches in Biological Sciences. 2013; 05(04): 413-18.

Mangram, A.J., Horan TC, Pearson ML, Silver LC, Jarvis WR. Guideline for prevention of surgical site infection, 1999. Hospital Infection Control Practices Advisory Committee.
Infection Control and Hospital Epidemiology. 1999; 20(4): 247-78.

Mawalla, B., Mshana SE, Chalya PL, Imirzalioglu $\mathrm{C}$ and Mahalu W. Predictors of surgical site infections among patients undergoing major surgery at Bugando medical centre in Northwestern Tanzania. BMC surgery. 2011;11(21):1-7.

Mundhada, A.S., Tenpe S. A study of organisms causing surgical site infections and their antimicrobial susceptibility in a tertiary care government hospital. Indian Journal of Pathology and Microbiology. 2015; 58(02):195-99.

Patel, S.M., Patel MH, Patel SD, Soni ST, Kinariwala DM, Vegad MM. Surgical site infections: incidence and risk factors in a tertiary care hospital, western India. National Journal of Community Medicine. 2012; 03(02):193-96.

Rahman, J., Sultana N, Hasan M, Begum HA. Factors of post-operative wound infection in abdominal surgeries of obstetrics and gynaecology department. J. Dhaka National Med Coll. Hos. 2011; 18(01):39-42.

Ramesh, A., Dharini R. Surgical site infections in a teaching hospital. Clinio microbiological and epidemiological profile. Int J Biol Med Res. 2012; 03(03): 2050-53.

Ranjan, K.P., Ranjan N, Gandhi S. Surgical site infections with special reference to methicillin resistant Staphylococcus aureus: experience from a tertiary care referral hospital in North India. International Journal of Research in Medical Sciences. 2013; 01(02): 108-11.

Rao, R., Sumathi S, Anuradha K, Venkatesh D, Krishna S. Bacteriology of Postoperative wound infections. Int $J$ Pharm Biomed Res. 2013; 04(02): 7276. 
Razavi, S.M., Ibrahimpoor M, Kashani AS, Jafarian A. Abdominal surgical site infections: incidence and risk factors at an Iranian teaching hospital. $B M C$ Surgery. 2005:1-5.

Sahu, S., Shergill J, Sachan P, Gupta P. Superficial incisional surgical site infection in elective abdominal surgeries- A prospective study. The Internet Journal of Surgery. 2009; 26(01):1-7.

Saxena, A., Singh MP, Brahmachari S, Banerjee M. Surgical site infection among postoperative patients of tertiary care centre in central India- A prospective study. Asian Journal of Biomedical and Pharmaceutical Sciences. 2013; 03(17): 41-44.

Shah, S., Singhal T, Naik R. A 4-year prospective study to determine the incidence and microbial etiology of surgical site infections at a private tertiary care hospital in Mumbai, India. American Journal of Infection Control. 2015; 43: 59-62.

Shahane, V., Bhawal S, Lele U. Surgical site infections: A one year prospective study in a tertiary care center. International
Journal of Health Sciences, Qassim University. 2012; 06(01):79-84

Shanthi, J., Shankar T, Balagurunathan R. The scenario of post-operative wound infection from a government hospital in South India. Journal of Microbiology and Biotechnology Research. 2012; 02(03): 396-401.

Sonawane, J., Kamath N, Swaminathan R, Dosani K. Bacterial profile of surgical site infections and their antibiograms in a tertiary care hospital in Navi Mumbai. Bombay Hospital Journal. 2010; 52(03):358-61.

Verma, A.K., Kapoor AK, Bhargava A. Antimicrobial susceptibility pattern of bacterial isolates from surgical wound infections in tertiary care hospital in Allahabad, India. Internet Journal of Medical Update. 2012; 07(01): 27-34.

Wassef, M.A., Hussein A, Abdul Rahman EM, El-Sherif RH. A prospective surveillance of surgical site infections: study for efficacy of preoperative antibiotic prophylaxis. African Journal of Microbiology Research. 2012; 06(12):3072-78.

\section{How to cite this article:}

Preethishree, P., Rekha Rai and Vimal Kumar, K. 2017. Aerobic Bacterial Profile of PostOperative Wound Infections and Their Antibiotic Susceptibility Pattern. Int.J.Curr.Microbiol.App.Sci. 6(9): 396-411. doi: https://doi.org/10.20546/ijcmas.2017.609.049 